\title{
Diagnose nutricional e índices fotossintéticos de erva-mate sob diferentes níveis de adubação com zinco
}

\author{
Samara Deschamps GELSLEICHTER ${ }^{1}$, Heloisa Milesky Alves MASSANEIROํㅜ Andrei de Souza da SILVA ${ }^{1}$, \\ Priscilla DORS ${ }^{1}$, David José MIQUELLUTI ${ }^{1}$, Mari Lucia CAMPOS ${ }^{*}$, Marcelo Alves MOREIRA ${ }^{1}$ \\ ${ }^{1}$ Centro de Ciências Agroveterinárias, Universidade do Estado de Santa Catarina, Lages, SC, Brasil. \\ *E-mail: mari.campos@udesc.br \\ (ORCID: 0000-0002-6569-2699; 0000-0002-0113-9720; 0000-0002-8496-6077; 0000-0003-1672-6327; \\ 0000-0002-7369-6163; 0000-0003-3250-2067; 0000-0002-8315-5248)
}

\begin{abstract}
Recebido em 24/02/2021; Aceito em 11/11/2021; Publicado em 17/12/2021.
RESUMO: A deficiência de zinco representa um problema de saúde pública. Uma das estratégias para melhorar essa questão consiste em biofortificação agronômica. O objetivo dessa pesquisa foi avaliar o teor de Zn na parte aérea (folhas e ramos) e o limite crítico de Zn para plantas de erva-mate submetidas a adubação com sulfato de Zn. O experimento foi conduzido em casa de vegetação no município de Lages. Foi utilizado Cambissolo Háplico Distrófico Típico, o qual foi submetido a análise química (Tedesco et al., 1995) e granulométrica (EMBRAPA, 1997). O delineamento experimental utilizado foi o inteiramente casualizado. As unidades experimentais foram compostas por vasos contendo $6 \mathrm{~kg}$ de solo, cinco doses de $\mathrm{Zn}(0,100,200,300$ e $\left.400 \mathrm{mg} \cdot \mathrm{kg}^{-1}\right)$ e sete repetições, totalizando 35 unidades experimentais. Foram realizadas análises antes da colheita (Índice SPAD, altura e Infrared Gas Analyser - IRGA) e análises após a colheita (peso fresco e seco de parte aérea, teor de $\mathrm{Ca}, \mathrm{Mg}, \mathrm{P}, \mathrm{Cu}, \mathrm{Zn}$ na folha). Os dados foram submetidos a análise de variância, com normalidade testada pelo teste de Shapiro-Wilk e a homogeneidade de variâncias pelo teste de Levenne, a nível de significância de 5\%. A aplicação de doses crescentes de $\mathrm{Zn}$ ao solo resultou em aumento do teor de $\mathrm{Zn}$ na parte aérea de forma linear. O teor médio de $\mathrm{Zn}$ na folha variou de $27 \mathrm{mg} \mathrm{kg}^{-1}$ na ausência de aplicação de $\mathrm{Zn}$ a $883 \mathrm{mg} \mathrm{kg}^{-1}$ na dose aplicado de $400 \mathrm{mg} \mathrm{kg}^{-1}$. Não houve diferença estatística para massa fresca, seca de parte aérea, índice SPAD, altura, condutância estomática e transpiração indicando ausência de estresse oxidativo. Não foi possível calcular o limite crítico de Zn para erva-mate.
\end{abstract}

Palavras-chave: biofortificação agronômica; Cambissolo; Ilex paraguariensis.

\section{Diagnose yerba mate nutritional and photosynthetic indices under different levels of zinc fertilization}

\begin{abstract}
Zinc deficiency represents a public health problem. One of the strategies to improve this issue is agronomic biofortification. The objective of this research was to evaluate the $\mathrm{Zn}$ content in the aerial part (leaves and branches) and the critical limit of $\mathrm{Zn}$ for yerba mate plants submitted to fertilization with $\mathrm{Zn}$ sulfate. The experiment was conducted in a greenhouse in the municipality of Lages. A typical Dystrophic Cambisol was used, which was subjected to chemical (Tedesco et al., 1995) and granulometric (EMBRAPA, 1997) analysis. The experimental design used was completely randomized. The experimental units were composed of pots containing $6 \mathrm{~kg}$ of soil, five doses of $\mathrm{Zn}\left(0,100,200,300\right.$ and $\left.400 \mathrm{mg} \cdot \mathrm{kg}^{-1}\right)$ and seven replications, totaling 35 experimental units. Analyzes were performed before harvesting (SPAD Index, height and Infrared Gas Analyzer - IRGA) and analyzes after harvesting (fresh and dry aerial weight, and $\mathrm{Ca}, \mathrm{Mg}, \mathrm{P}, \mathrm{Cu}, \mathrm{Zn}$ content in the leaf). The data were submitted to analysis of variance, with normality tested by the Shapiro-Wilk test and homogeneity of variances by the Levenne test, at a significance level of $5 \%$. The application of increasing doses of $\mathrm{Zn}$ to the soil resulted in a linear increase in the $\mathrm{Zn}$ content in the aerial part. The average $\mathrm{Zn}$ content in the leaf varied from $27 \mathrm{mg} \mathrm{kg}^{-1}$ in the absence of $\mathrm{Zn}$ application to $883 \mathrm{mg} \mathrm{kg}^{-1}$ at the applied dose of $400 \mathrm{mg} \mathrm{kg}^{-}$ 1. There was no statistical difference for fresh, dry shoot weight, SPAD index, height, stomatal conductance and perspiration indicating absence of oxidative stress. It was not possible to calculate the critical limit of $\mathrm{Zn}$ for yerba mate.
\end{abstract}

Keywords: biofortification agronomic; Cambisol; Ilex paraguariensis.

\section{INTRODUÇÃO}

A Erva-mate é uma espécie florestal com área de ocorrência natural na região Sul do Brasil, Nordeste da Argentina e Leste do Paraguai, botanicamente chamada de Ilex paraguariensis St. Hill.

O uso da planta tradicionalmente conhecido são as infusões, com água quente gerando o chimarrão e com água fria o tererê. Entretanto, seu uso pode ir muito além disso, é utilizada também na área estética compondo cremes e máscaras faciais, na culinária, na indústria alimentícia compondo balas e gomas, além do uso na indústria farmacêutica em encapsulados, comprimentos, e extratos visando as propriedades medicinais. São os diferentes grupos químicos que a erva-mate apresenta em sua composição que conferem a ela esses inúmeros usos. Dentre eles destacam-se: 
as saponinas, os alcaloides, os compostos fenólicos e os óleos essenciais que atuam como antioxidantes, estimulantes, combatendo micróbios e realizando a eliminação da retenção de líquidos. Vitaminas e minerais também são presentes na sua composição (SIMÕES et al., 2001).

Esses compostos estão associados a uma série de benefícios para saúde humana. Foram realizados experimentos para comprovação, sendo a maioria feita com ratos. O substrato utilizado foi o extrato da erva (sólido) ou o chá (líquido) os resultados obtidos foram a perda de peso, ação anticonvulsivante, antidepressiva, atenuação da glicemia e do colesterol (ARÇARI et al., 2011; ARZI et al., 2011; MARTIN et al., 2013; REIS et al., 2013; PEREIRA et al., 2012).

Objetivando aumentar a concentração de micronutrientes nos vegetais, uma das estratégias consiste na biofortificação agronômica (CAKMAK, 2008) que tem como intuito suprir a demanda diária necessária de micronutrientes que muitas vezes se encontra em déficit, principalmente em pessoas que vivem em países em desenvolvimento. Dentre os nutrientes com maior frequência de deficiência destacamse ferro (Fe), iodo (I), selênio (Se) e o zinco ( $\mathrm{Zn}$ ).

A deficiência de $\mathrm{Zn}$ em humanos interfere no funcionamento do sistema imunológico, que consequentemente pode gerar maiores chances de se ter infecções, prejudica o crescimento físico, retarda capacidade de aprendizagem além de estar relacionado a danos na duplicação do DNA (DEMMENT et al., 2003; BHUTTA et al., 2004; GIBSON, 2006; PRASAD, 2007, HAASE et al., 2020; JOO et al., 2021).

A erva-mate pode ser uma planta com potencial para programas de biofortificação com Zn. É uma planta calcífuga, ou seja, que se desenvolve bem em solos ácidos e com altos teores de alumínio(CARVALHO, 2003) e outros elementos-traço, o que, pode indicar que a erva-mate possui capacidade de responder ao aumento de $\mathrm{Zn}$ (elemento-traço) no solo, aumentando por consequência o teor na parte aérea e na infusão (chimarrão).

Dessa forma o objetivo dessa pesquisa foi avaliar o teor de $\mathrm{Zn}$ na parte aérea (folhas e ramos), e determinar o limite crítico de $\mathrm{Zn}$ para plantas de erva-mate submetidas a adubação com sulfato de $\mathrm{Zn}$ a fim de verificar seu potencial para uso em biofortificação agronômica.

\section{MATERIAL E MÉTODOS}

O experimento foi conduzido em casa de vegetação do Departamento de Solos e Recursos Naturais da UDESC, no munícipio de Lages, SC. O delineamento utilizado foi o inteiramente casualizado, as unidades experimentais foram compostas por vasos contendo $6 \mathrm{Kg}$ de solo com 5 doses crescentes de zinco $\left(0,100,200,300\right.$ e $\left.400 \mathrm{mg} \cdot \mathrm{kg}^{-1}\right)$ na forma de sulfato de zinco, sendo que, cada dose foi composta de 7 repetições.

O solo utilizado foi um Cambissolo Háplico Distrófico Típico derivado de arenito botucatu, coletado na localidade de Pedras Brancas/SC. Esse solo foi seco ao ar, tamisado em peneira de malha $4 \mathrm{~mm}$, retirada uma amostra para realização de análise granulométrica (método do densímetro de Boyoucus, EMBRAPA,1997), e análise química (TEDESCO et al., 1995). Os micronutrientes $\mathrm{Cu}$ e $\mathrm{Zn}$ foram extraídos em $\mathrm{HCl}$ 0,1 M e quantificados em espectrofotômetro de absorção atômica com atomização em chama ar acetileno (EAA Perkin Elmer 200 ®). A CTC foi determinada a pH do solo através da soma dos cátions $\mathrm{Ca}, \mathrm{Mg}, \mathrm{Na}, \mathrm{K}$ e $\mathrm{Al}$, e em $\mathrm{pH} 7$, pela soma dos cátions anteriores juntamente com o $\mathrm{H}^{+}$.

As mudas de erva-mate utilizadas foram provenientes da empresa Eucaflora Florestal, sendo estas certificadas pela EPAGRI Chapecó/SC. O pH do solo foi corrigido para 5,5. Antes do plantio foi realizado a adubação com sulfato de zinco e uma semana após o plantio a adubação com superfosfato triplo (SFT), cloreto de potássio e ureia, nas quantidades 20,20 e $30 \mathrm{~kg} /$ ha respectivamente. A adubação foi realizada de acordo com o manual de adubação e calagem para os estados do Rio Grande do Sul e Santa Catarina, seguindo as recomendações para a cultura. Durante toda a condução do experimento o teor de umidade do solo foi mantido a $75 \%$ da capacidade de campo (CC).

\subsection{Analises antes da colheita}

A medida do índice SPAD foi feita através do medidor portátil de clorofila SPAD 502 (Konica Minolta ${ }^{\circledR}$ ) com objetivo de obter os valores de intensidade do verde das folhas, sendo coletado durante o experimento em dois momentos (30 dias após o plantio e no dia da colheita). Para tanto, foram selecionadas folhas totalmente expandidas, sem injúrias ou sintomas de doenças visíveis. As medidas foram realizadas no terço médio das plantas, sempre em duplicata, em todas as plantas de cada repetição. A medida da altura da planta foi realizada no dia da colheita padronizada por meio da medida da base da planta até a inserção da última folha no caule. No dia da colheita foi realizada as medidas de taxa fotossintética líquida (A) das plantas com auxílio de analisador de gases por infravermelho portátil (IRGA) equipado com uma câmara foliar com fonte de LED (LI6400XT Portable Photosynthesis and Fluorescence System; LICOR, Lincoln, EUA). Esta leitura foi realizada na mesma folha selecionada para a leitura do índice SPAD. A colheita foi realizada quando da estabilização do crescimento da planta de erva-mate.

\subsection{Análises após a colheita}

Após a colheita foram avaliados o peso fresco e seco de parte aérea (folhas e ramos), e o teor dos nutrientes $\mathrm{Ca}, \mathrm{Mg}$, $\mathrm{Cu}$, e $\mathrm{Zn}$ na parte aérea. Os teores dos nutrientes foram determinados utilizando-se o método de extração USEPA 3050B e quantificação em espectrômetro de emissão atômica com plasma acoplado por indução (ICP-OES). A confiabilidade do método foi aferida utilizando material referência de planta CRM-Agro E1001a (FO-01/12) EMBRAPA. As raízes foram limpas e lavadas com água destilada, e mantidas em uma solução de álcool 50\%, para posterior determinação de parâmetros radiculares tais como volume, diâmetro médio e comprimento radicular. Para determinação de tais parâmetros, as raízes foram distribuídas uniformemente em cuba de vidro preenchida por lâmina de água destilada, sem sobreposição, e submetidas à digitalização em scanner profissional. As imagens obtidas do processo de scanner foram processadas através do programa computacional WinRhizo.

Para a construção de um cenário hipotético de ingestão de $\mathrm{Zn}$ por um adulto foi considerado o consumo de $1 \mathrm{~L}$ de chimarrão e o uso de $100 \mathrm{~g}$ de erva-mate.

\subsection{Análise estatística}

Os dados obtidos foram submetidos a análise de variância, com normalidade testada pelo teste de ShapiroWilk e a homogeneidade de variâncias pelo teste de Levene, 
a nível de significância de 5\%. As análises foram realizadas utilizando o programa $\mathrm{R}^{\circledR}$ (R DEVELOPMENT CORE TEM, 2012).

\section{RESULTADOS}

O aumento do teor de $\mathrm{Zn}$ aplicado no solo resultou em aumento linear do $\mathrm{Zn}$ na folha (Figura 1). O teor de $\mathrm{Zn} \mathrm{da}$ parte aérea na testemunha foi em média $27,22 \mathrm{mg} \cdot \mathrm{kg}^{-1}$ enquanto que na dose $400 \mathrm{mg} \cdot \mathrm{kg}^{-1}$ o teor foi $883,03 \mathrm{mg} \cdot \mathrm{kg}^{-1}$ de Zn.

Os teores dos elementos de $\mathrm{Ca}, \mathrm{Mg}, \mathrm{P}$ e Cu na parte aérea da erva-mate podem ser encontrados nas Figuras 2, 3, 4 e 5, respectivamente. Para $\mathrm{Ca}, \mathrm{Mg}$ e $\mathrm{P}$ ocorreu diminuição do teor na parte aérea a partir da dose de $200 \mathrm{mg} \cdot \mathrm{kg}^{-1}$ de $\mathrm{Zn}$ aplicada ao solo. Não foi possível ajustar uma equação aos teores de $\mathrm{Cu}$ na parte aérea.

Não houve diferenças significativas entre doses de $\mathrm{Zn}$ para altura da planta, peso seco e fresco de folhas e ramos, diâmetro, comprimento e volume de raiz (Tabela 1) e para intensidade do verde da folha, taxa fotossintética, condutância estomática e transpiração (Tabela 2).

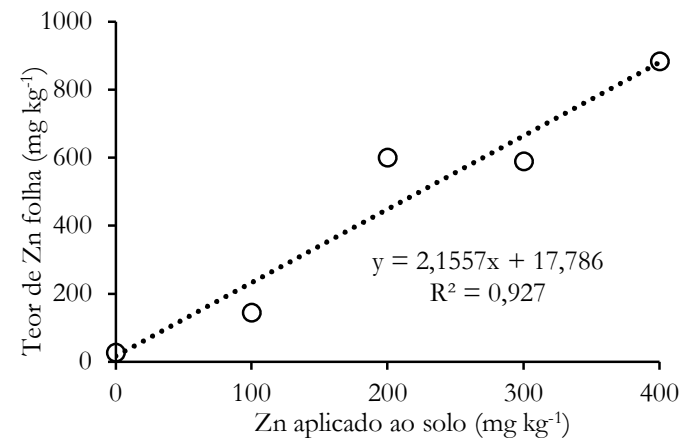

Figura 1. Teor de Zn nas folhas de erva mate em função das doses de $\mathrm{Zn}$ aplicados no solo.

Figure 1. $\mathrm{Zn}$ content in mate leaves as a function of $\mathrm{Zn}$ doses applied to the soil.

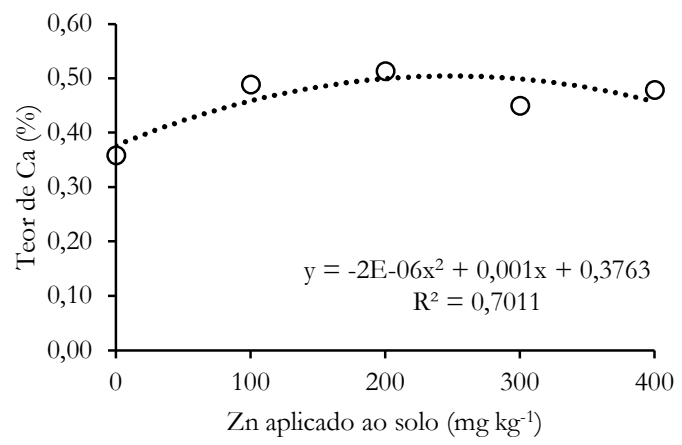

Figura 2. Teores médios de Ca na parte aérea da erva mate em função das doses crescentes de $\mathrm{Zn}$ aplicados ao solo.

Figure 2. Mean contents of $\mathrm{Ca}$ in the aerial part of mate as a function of increasing doses of $\mathrm{Zn}$ applied to the soil.

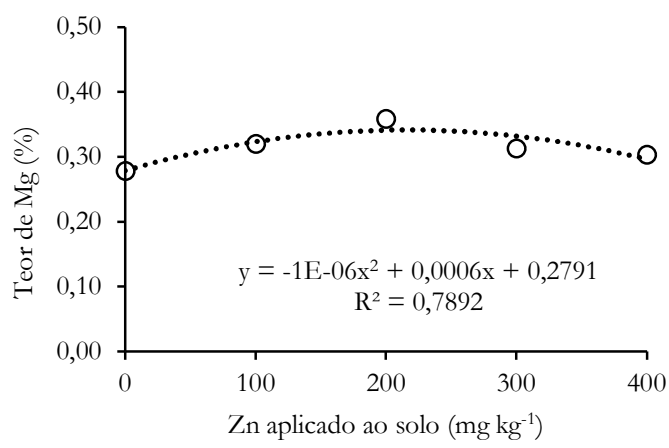

Figura 3. Teores médios de magnésio na parte aérea da erva mate em função das doses crescentes de $\mathrm{Zn}$ aplicados ao solo.

Figure 3. Average contents of magnesium in the aerial part of mate as a function of increasing doses of $\mathrm{Zn}$ applied to the soil.

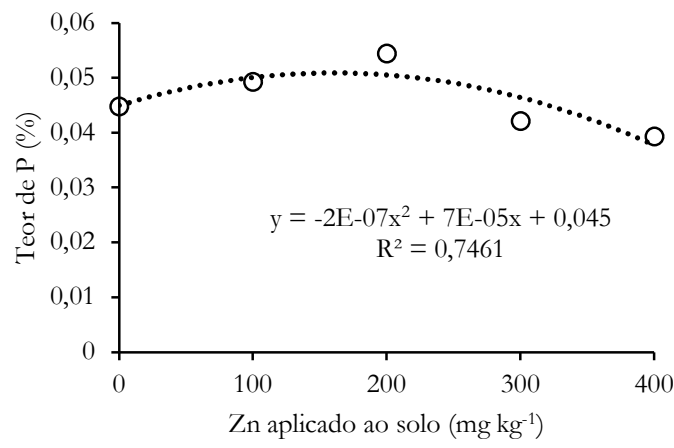

Figura 4. Teores médios de fósforo na parte aérea da erva mate em função das doses crescentes de $\mathrm{Zn}$ aplicados ao solo.

Figure 4. Average contents of phosphorus in the aerial part of mate as a function of increasing doses of $\mathrm{Zn}$ applied to the soil.

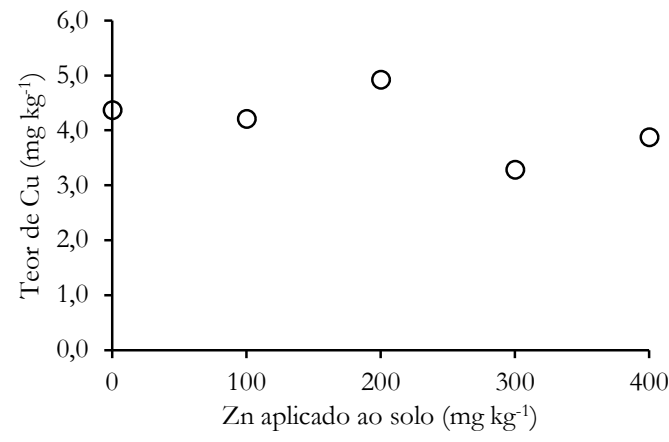

Figura 5. Teores médios de cobre na parte aérea da erva mate em função das doses crescentes de $\mathrm{Zn}$ aplicados ao solo.

Figure 5. Average contents of copper in the aerial part of mate as a function of increasing doses of $\mathrm{Zn}$ applied to the soil.

Tabela 1. Valor médio para cada variável (adimensional) obtida pela divisão da média das doses 100, 200, 300 e $400 \mathrm{mg} \mathrm{kg}^{-1}$ pela média da testemunha.

Table 1. Mean value for each variable (dimensionless) obtained by dividing the mean of the doses 100, 200, 300 and $400 \mathrm{mg} \mathrm{kg}-1 \mathrm{by}$ the mean of the control.

\begin{tabular}{ccccccccc}
\hline \multirow{2}{*}{$\begin{array}{c}\text { Zn solo } \\
\left(\mathrm{mg} \mathrm{kg}^{-1}\right)\end{array}$} & \multirow{2}{*}{ Altura } & \multicolumn{2}{c}{ Peso Fresco } & \multicolumn{2}{c}{ Peso Seco } & \multicolumn{3}{c}{ Raiz } \\
\cline { 2 - 9 } & & Raiz & Folha & Raiz & Folha & Diâmetro & Comprimento & Volume \\
\hline 100 & 0,93 & 0,99 & 0,84 & 1,00 & 0,95 & 1,05 & 0,80 & 0,85 \\
200 & 0,98 & 1,09 & 0,92 & 1,03 & 1,11 & 0,95 & 0,91 & 0,8 \\
300 & 1,00 & 1,12 & 0,72 & 1,10 & 0,93 & 1,03 & 0,87 & 0,93 \\
400 & 1,04 & 1,06 & 0,79 & 1,09 & 1,27 & 0,99 & 0,81 & 0,81 \\
\hline
\end{tabular}


Tabela 2. Valor médio para cada variável (adimensional) obtida pela divisão da média das doses 100, 200, 300 e $400 \mathrm{mg} \mathrm{kg}^{-1}$ pela média da testemunha.

Table 2. Mean value for each variable (dimensionless) obtained by dividing the mean of the doses 100, 200, 300 and $400 \mathrm{mg} \mathrm{kg}-1 \mathrm{by}$ the mean of the control.

\begin{tabular}{cccccc}
\hline $\begin{array}{c}\text { Zn solo } \\
\left(\mathrm{mg} \mathrm{kg}^{-1}\right)\end{array}$ & SPAD 1 & SPAD 2 & $\begin{array}{c}\text { Taxa } \\
\text { Fotossintética }\end{array}$ & $\begin{array}{c}\text { Condutância } \\
\text { Estomática }\end{array}$ & Transpiração \\
\hline 100 & 1,16 & 1,13 & 0,92 & 0,78 & 1,11 \\
200 & 1,17 & 1,39 & 1,01 & 1,09 & 1,01 \\
300 & 1,14 & 1,11 & 1,01 & 0,93 & 1,08 \\
400 & 1,09 & 1,19 & 1,11 & 0,98 & 1,13 \\
\hline
\end{tabular}

SPAD - intensidade do verde da folha, SPAD 1 realizado 30 dias após o plantio SPAD 2 no dia da colheita.

A Figura 6 apresenta os cenários hipotéticos $(\mathrm{CH}) 1$ e 2 onde 14 e $60 \mathrm{mg}$ de $\mathrm{Zn}$ seriam a quantidade do elemento obtido (ou absorvido) por um adulto pelo consumo de $1 \mathrm{~L}$ de chimarrão e 100 gramas de erva-mate cultivada sob aplicação de 100 e $200 \mathrm{mg} \mathrm{kg}^{-1}$ de $\mathrm{Zn}$ no solo, respectivamente. Para adultos, mulheres grávidas e lactantes, os valores de ingestão diária recomendada estão entre $7 \mathrm{mg} /$ dia a $16 \mathrm{mg} /$ dia, dependendo do sexo e da ingestão de fitatos na dieta (HAASE e al., 2020). Para CH1 o teor de Zn é muito próximo ao Ingestão Diária Recomendada (IDR), enquanto que no $\mathrm{CH} 2$ a quantidade de $\mathrm{Zn}$ seria cinco vezes superior a IDR.

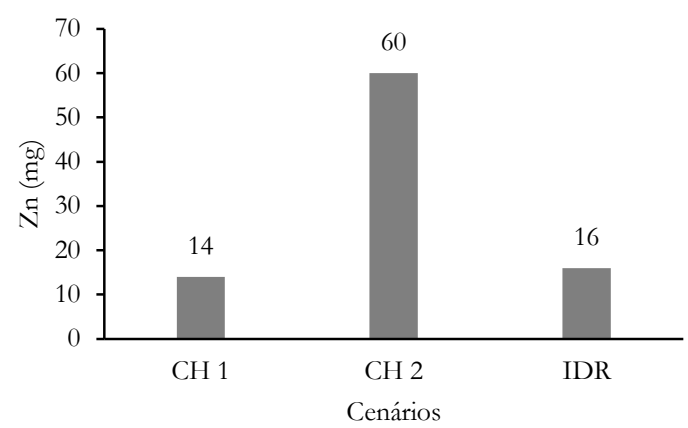

Figura 6: Ingestão média de Zn pelo consumo de $1 \mathrm{~L}$ de chimarrão calculado para erva mate cultivada nas doses de $\mathrm{Zn}$ de $100 \mathrm{mg} \cdot \mathrm{kg}^{-1}$ (CH1) e $200 \mathrm{mg} \mathrm{kg}^{-1}$ (CH2) aplicadas ao solo e Valor de Ingestão Diária Recomendada (IDR) para um adulto, segundo Joo et al. (2021).

Figure 6: Average $\mathrm{Zn}$ intake by consuming $1 \mathrm{~L}$ of herb tea calculated for mate cultivated in $\mathrm{Zn}$ doses of $100 \mathrm{mg} \mathrm{kg}^{-1}$ (CH1) and $200 \mathrm{mg}$ $\mathrm{kg}^{-1}(\mathrm{CH} 2)$ applied to the soil and Recommended Daily Intake Value (RDI) for an adult, according to Joo et al. (2021).

\section{DISCUSSÃO}

Estudos científicos têm apontado que a erva mate é capaz de translocar e acumular Pb (SILVA et al., 2019), As e Cd (PARDINHO et al., 2020), Ca e Mn (MOTA et al., 2021) nas folhas e que a erva mate é uma hiperacumuladora de $\mathrm{Mn}$ (MAGRI et al., 2021). Magri et al. (2021) e Matos et al. (2021) observaram correlação positiva entre teor de $\mathrm{Zn}$ no solo e teor na folha da erva-mate coletada em diferentes regiões produtoras no sul do Brasil, porém não há estudos científicos publicados sobre absorção e acumulo de $\mathrm{Zn}$ em plantas de erva mate.

Os teores de $\mathrm{Zn}$ nas folhas (na dose $400 \mathrm{mg} \cdot \mathrm{kg}^{-1}$ o teor foi 883,03 mg. $\mathrm{kg}^{-1}$ de $\mathrm{Zn}$ ) observados no presente estudo podem indicar capacidade de hiperacumulação de Zn. Magri e colaboradores (2021) avaliaram a capacidade de acumulo de Mn em plantas de erva mate. Os autores usaram solos de diferentes materiais de origem (basalto e arenito), com e sem calagem, e seis doses de Mn (0, 30, 90, 270, 540 e $1.080 \mathrm{mg}$ $\mathrm{kg}^{-1}$ ) e cultivaram as plantas por 203 dias. As plantas foram capazes de acumular nas folhas, na dose de $540 \mathrm{mg} \mathrm{kg}-1$ aplicada no solo, entre 13.452,0 (solo derivado de arenito) e 12.127,0 mg. $\mathrm{kg}^{-1}$ (solo derivado de basalto).

Para uma planta ser considerada hiperacumuladora é necessário ser capaz de translocar para parte aérea um ou mais elementos inorgânicos em níveis até cem vezes maiores que outras espécies, crescendo sob as mesmas condições. Dessa forma para a planta de erva mate ser considerada como hiperacumuladora são necessários outros experimentos que utilizem maiores doses de $\mathrm{Zn}$ para verificar a capacidade de acumulação do metal sem prejuízo ao desenvolvimento da planta. Assim como são necessárias pesquisas futuras para se obter o valor do limite crítico (LC) de Zn para erva-mate, ou seja, o teor de zinco na parte aérea que resulta em redução de $10 \%$ de massa seca da planta.

Os valores apresentados nas tabelas 1 e 2 indicam que valores próximos de 1,0 não houve diferença entre a dose zero e as demais doses de $\mathrm{Zn}$ aplicadas ao solo. Geralmente teores foliares acima de $300 \mathrm{mg} \mathrm{kg}^{-1}$ de $\mathrm{Zn}$ tem efeito de toxicidade para a maioria das plantas (LIN; AARTS, 2012), para erva-mate isso não se confirmou, já que ela não apresentou redução de altura, de matéria seca, e de taxa fotossintética. Quando a planta está sob excesso de Zn, pode ocorrer uma diminuição no seu peso seco (PS) e fresco (PF), pela menor produção de fotoassimilados, devido, a redução das taxas fotossintéticas. O estresse causado por excesso de Zn pode levar a alterações no aparato fotossintético, devido a competição e substituição do magnésio (ativador da enzima) por esse elemento comprometendo dessa forma a atividade da enzima rubisco (VAN; CLIJSTERS, 1986).

A ausência de efeito para os parâmetros transpiração e condutância estomática (tabela 1) sugerem possível compartimentalização do zinco nas células da folha, evitando assim, danos aos processos fisiológicos. Estudos mostram que a sensibilidade ao $\mathrm{Zn}$ varia conforme a dose aplicada e a espécie vegetal. Existem plantas com alta tolerância a esse elemento, podendo atingir teor de $20 \mathrm{~g} \mathrm{~kg}^{-1}$ de Zn (KUPPER et al., 1999). Porém existem plantas que apresentam sintomas de toxidez com baixa quantidade do elemento como a cultura do cafezeiro. Cambrollé et al. (2013) observaram que doses de $\mathrm{Zn}$ acima de $90 \mathrm{mmol} \mathrm{\textrm {L } ^ { - 1 }}$ (5886 mg.kg-1) foram responsáveis pelo declínio na atividade fotossintética, em Limoniastrum monopetalum (L.).

De maneira geral, quando ocorre estresse oxidativo temse produção de espécies reativas ao oxigênio, como superóxido $\left(\mathrm{O}_{2}^{-}\right)$, radicais hidroxila $\left(\mathrm{OH}^{-}\right)$e peróxido de hidrogênio $\left(\mathrm{H}_{2} \mathrm{O}_{2}\right)$ que, ao interagirem com componentes celulares, promovem danos oxidativo em ácidos nucleicos, proteínas, açúcares e lipídios, o que, em condições extremas acarretam em morte celular (GADJEV et al., 2008). Tais danos não foram observados no presente estudo. 
Nas figuras 2, 3, 4 e 5 tem-se os teores dos elementos de $\mathrm{Ca}, \mathrm{Mg}, \mathrm{P}$ e $\mathrm{Cu}$ na parte aérea da erva-mate. A queda nos teores de cálcio e magnésio com o aumento das doses de $\mathrm{Zn}$ se deve a competição no momento da absorção entre os cátions divalentes $\mathrm{Ca}^{+2}, \mathrm{Mg}^{+2}$ e $\mathrm{Zn}^{+2}$, gerando o chamado efeito antagônico (KABATA-PENDIAS, 2000). Comportamento semelhante foi observado por Soares et al. (2001) trabalhando com eucalipto, em solução nutritiva. Já a diminuição no teor de fósforo pode estar relacionada com a precipitação do fósforo no solo na forma de fosfato de zinco, acarretando imobilização do elemento. Quanto aos teores do elemento $\mathrm{Cu}$ não foi possível ajustar uma equação, o que pode indicar que o aumento no $\mathrm{Zn}$ não interferiu diretamente na absorção e translocação do Cu.

A erva-mate responde a adubação com $\mathrm{Zn}$ e pode ser uma importante fonte deste na dieta dos consumidores de chimarrão, entretanto, o cálculo de ingestão diária de Zn leva em consideração a quantidade de calorias ingeridas (JOO et al., 2021) e o teor de fitatos na dieta (HAASE et al., 2020), o que não foi considerado nos cenários hipotéticos 1 e 2 do presente estudo.

O Zinco é essencial a saúde humana, por estar envolvido na replicação do DNA (MEHRI, 2020) e divisão celular, nos processos catalíticos enzimático, no metabolismo de energia e no crescimento. (CRUZ; SOARES, 2011; JOO et al., 2021). Dietas com baixa ingestão de zinco podem aumentar o risco de desenvolvimento de doenças renais crônicas em indivíduos com função renal normal (JOO et al., 2021). Os humanos são tolerantes à ingestão de até $100 \mathrm{mg} /$ dia de $\mathrm{Zn}$. Nos casos de envenenamento agudo suas manifestações incluem náuseas, vômitos, diarreia, febre e letargia (MEHRI, 2020)

\section{CONCLUSÕES}

A aplicação de doses crescentes de $\mathrm{Zn}$ ao solo resultou em aumento do teor de $\mathrm{Zn}$ na parte aérea de forma linear;

A erva mate acumulou $883,03 \mathrm{mg} \cdot \mathrm{kg}^{-1}$ de $\mathrm{Zn}$ na parte aérea na maior dose aplicada de $\mathrm{Zn}$ ao solo;

Não houve diferença estatística para massa fresca, seca de parte aérea, índice SPAD, altura, condutância estomática, transpiração e parâmetros radiculares indicando ausência de estresse oxidativo;

Doses de $\mathrm{Zn}$ acima de $200 \mathrm{mg} \cdot \mathrm{kg}^{-1}$ conduziram a redução dos teores $\mathrm{Ca}, \mathrm{P}$ e $\mathrm{Mg}$ nas folhas.

Não foi possível calcular o limite crítico de Zn para ervamate.

\section{AGRADECIMENTOS}

Os autores agradecem a Coordenação de Aperfeiçoamento de Pessoal de Nível Superior (CAPES), a Fundação de Amparo à Pesquisa e Inovação do Estado de Santa Catarina (FAPESC) e a Universidade do Estado de Santa Catarina (UDESC) pelo apoio financeiro. Agradecem também a EMBRAPA pela concessão do material de referência RM-Agro E1001a (FO-01/12).

\section{REFERÊNCIAS}

ARÇARI, D. P.; BORZOLAN, V. P.; RODRIGUES, E. R.; MARTINS, F.; LIMA, R. J.; SAWAYA, A. C. H. F.; CARVALHO, P. O. Effect of mate tea (Ilex paraguariensis) supplementation on oxidative stress biomarkers and LDL oxidisability in normo-and hyperlipidaemic humans. Journal of Functional Foods, v. 3, n. 3, p. 190-197, 2011. DOI: https://doi.org/10.1016/j.jff.2011.04.001.

ARZI, A.; AHAMEHE, M.; SARAHROODI, S. Effect of hydroalcoholic extract of Lavandula officinalis on nicotine-induced convulsion in mice. Pakistan Journal of Biological Sciences, v. 14, n. 11, p. 634-640, 2011. https://doi.org/10.3923/pjbs.2011.634.640

CAKMAK, I.; KALAYCI, M.; KAYA, Y.; TORUN, A.A.; AYDIN, N.; WANG, Y.; ARISOY, Z.; ERDEM, H.; YAZICI, A.; GOKMEN, O.; OZTURK, L.; HORST, W.J. Biofortification and localization of zinc in wheat grain. Journal Agric Food Chem, v. 58, p. 9092-9102, 2010. DOI: https://doi.org/10.1021/jf101197h

CARVALHO, P. E. R. Espécies Arbóreas Brasileiras: Coleção Espécies Arbóreas Brasileiras, vol. 1. Brasília: Embrapa Informações Tecnológica; Colombo, PR: Embrapa Florestas, 2003. 1039p.

CRUZ, J. B. F.; SOARES, H. F. Uma revisão sobre o zinco Ensaios e Ciência: Ciências Biológicas, Agrárias e da Saúde, v. 15, n. 1, p. 207-222, 2011.

DEMMENT, M. W.; YOUNG, M. M.; SENSENIG, R. L. Providing micronutrients through food-ased solutions: A key to human and national development. The Journal of Nutrition, v. 133, n. 11, p. 3879S-3885S, 2003. DOI: https://doi.org/10.1093/jn/133.11.3879S.

GADJEV, I.; STONE, J. M.; GECHEV, T. S. Programmed cell death in plants: new insights into redox regulation and the role of hydrogen peroxide. International Review of Cell and Molecular Biology, v. 270, p. 87-144, 2008. DOI: https://doi.org/10.1016/S1937-6448(08)01403-2.

GIBSON, R. Zinc: The missing link in combating micronutrient malnutrition in developing countries. Proceedings of the Nutrition Society, v. 65, n. 1, p. 51 60, 2006. DOI: https://doi.org/10.1079/PNS2005474.

HAASE, H.; ELLIGER, S.; BERTHOLD, N.; RICHTER, M. Revised D-A-CH-reference values for the intake of zinc, Journal of Trace Elements in Medicine and Biology, v. 61, p. 1-8, 2020. DOI: https://doi.org/10.1016/j.jtemb.2020.126536

BHUTTA, Z.; GIBSON, R. S.; KING, J. C.; LÖNNERDAL, B.; RUEL, M. T.; SANDTRÖM, B.; WASANTWISUT, E.; HOTZ, C. Assessment of the risk of zinc deficiency in populations and options for its control. Food and Nutrition Bulletin, v. 25, n.1 (suppl), 2004. https://doi:10.1177/15648265040251S205

JOO, Y. S.; KIM, H. W.; LEE, S.; NAM, K. L.; YUN, H. R.; JHEE, J. H.; HAN, S. H.; YOO, T. H.; KANG, S. W.; PARK, T. J. Dietary zinc intake and incident chronic kidney disease. Clinical Nutrition, v. 40, p. 1039-1045, 2021. DOI: https://doi.org/10.1016/j.clnu.2020.07.005

KABATA-PENDIAS, A. Trace elements in soils and plants. 4 ed. CRC Press, 2010. 548p.

KUPPER, H.; ZHAO, F. J.; MCGRATH, S. P. Cellular Compartmentation of Zinc in Leaves of the Hyperaccumulator Thlaspi caerulescens. Plant Physiology, v. 119, n. 1, p. 305-312, 1999. DOI: https://doi.org/10.1104/pp.119.1.305.

LIN, Y.; AARTS, M. G. M. The molecular mechanism of zinc and cadmium stress response in plants. Cellular and Molecular Life Sciences, v. 69, n. 19, p. 3187-3206, 2012. DOI: https://doi.org/10.1007/s00018-012-1089$\mathrm{z}$. 
MAGRI, E.; GUGELMIN, E. K.; GRABARSKI, F. A. P.; BARBOSA, J. Z.; AULER, A. C.; WENDLING, I.; PRIOR, S. A.; VALDUGA, A. T.; MOTTA, A. C. V. Manganese hyperaccumulation capacity of Ilex paraguariensis A. St. Hil. And occurrence of interveinal chlorosis induced by transient toxicity. Ecotoxicology and Environmnetal Safety, v. 203, p. 1-8, 2020. DOI: https://doi.org/10.1016/j.ecoenv.2020.111010.

MAGRI, E.; VALDUGA, A. T.; GONÇALVES, I. L.; BARBOSA, J. Z.; RABEL, D. O.; MENEZES, I. M. N. R.; NASCIMENTO, P. A. N.; OLIVEIRA, A.; CORREA, R. S.; MOTTA, A. C. V. Cadmium and lead concentrations in yerba mate leaves from agroforestry and plantation systems: An international survey in South America. Journal of Food Composition and Analysis, v. $96, \quad$ p. 1-10, 2021. DOI: https://doi.org/10.1016/j.jfca.2020.103702.

MARTIN, J. G.; PORTO, E.; ALENCAR, S. M. de; GLÓRIA, E. M. da; CORRÊAA, C. B.; CABRAL, I. S. R. Antimicrobial activity of yerba mate (Ilex paraguariensis St. Hil.) against food pathogens. Revista Argentina de microbiologia, v. 45, n. 2, p. 93-98, 2013. DOI https://doi.org/10.1016/S0325-7541(13)70006-3.

MEHRI, A. Trace Elements in Human Nutrition (II) - An Update. International Journal of Preventive Medicine, v. 11, n. 2, p. 1-17, 2020. DOI: https://doi.org/10.4103/ijpvm.IJPVM_48_19

MOTTA, A. C.; BARBOSA, J. Z.; MAGRI, E.; PEDREIRA, G. Q.; SANTIN, D.; PRIOR, S. A.; CONSALTER, R.; YOUNG, S. D.; BROADLEY, M. R.; BENEDETTI, L. E. Elemental composition of yerba mate (Ilex paraguariensis A.St.-Hil.) under low input systems of southern Brazil. Science of The Total Environment, v. 736, n. 20, e139637, 2020. DOI: https://doi.org/10.1016/j.scitotenv.2020.139637

PARDINHO, R. B.; VECCHIA, P. D.; ALVES, C. M. A. C.; PIMENTEL, N.; GAZZANA, D.; BOLZAN, R. C; DUARTE, F. A.; BISOGNIN, A. A.; FLORES, E. M. M. Ilex Paraguariensis exposition to $\mathrm{As}$ and $\mathrm{Cd}$ in a closed soilless system. Chemosphere, v. 258, p. 1-8, 2020. DOI: https://doi.org/10.1016/j.chemosphere.2020.127284

PEREIRA, D. F.; KAPPEL, V. D.; CAZAROLLI, L. H.; BOLIGON, A. A.; ATHAYDE, M. L.; GUESSER, S. M.; DA SILVA, E. L.; SILVA, F. R. M. B. Influence of the traditional Brazilian drink Ilexparaguariensis tea on glucose homeostasis. Phytomedicine, v. 19, n. 10, p. 868-877, 2012.2 DOI: https://doi.org/10.1016/j.phymed.2012.05.008

PRASAD, A. S. Zinc: mechanisms of host defense. The Journal of Nutrition, v. 137, n. 5, p. 1345-1349, 2007. https://doi.org/10.1093/jn/137.5.1345

REIS, E. M.; RÖPKE, J.; BUSANELLO, P. R.; LEAL, C. Q.; WAGNER, C.; BOLIGON, A. A.; ATHAYDE, M. L.; FACHINETTO, R. Effect of Hypericum perforatum on different models of movement disorders in rats. Behavioural pharmacology, v. 24, n. 7, p. 623-627, 2013.

DOI: https://doi.org/10.1097/FBP.0b013e3283656d68

SILVA, A. S.; CAMPOS, M. L.; MIQUELUTTI, D. J.; PEREIRA, E. R.; DORS, P. Physiological response of mate herb cultivated in lead contaminated soil: effects of exposure to the trace element. Ciência e Técnica Vitivinícola, v. 34, n. 3, p. 125-145, 2019.
SIMÕES, C. M. O. Farmacognosia: da planta ao medicamento. 3 ed. Florianópolis: UFSC, 2001. 833p.

SOARES, C. R. F. S.; GRAZZIOTI, P. H.; SIQUEIRA, J. O.; CARVALHO, J. G. de; MOREIRA, F. M. S. Toxidez de zinco no crescimento e nutrição de Eucalyptus maculata e Eucalyptus urophylla em solução nutritiva. Pesquisa Agropecuária Brasileira, v. 36, n. 2, p. 339348, 2001. DOI: https://doi.org/10.1590/S0100204X2001000200018

VAN, A. F.; CLIJSTERS, H. Inibição da fotossíntese em Phaseolus vulgaris por tratamento com concentração tóxica de zinco: efeito na ribulose-1, 5bisfosfato carboxilase/oxigenase. Journal of Plant Phy siology, v. 125 , n. 3-4, p. 355-360, 1986. DOI: https://doi.org/10.1002/pld3.357 